\section{INCIDENCE AND TOTAL LIFETIME COSTS OF MOTOR VEHICLE-RELATED FATAL AND NON-FATAL INJURY BY ROAD USER TYPE IN THE UNITED STATES}

R B Naumann, A M Dellinger*, EZaloshnja, B A Lawrence, TR Miller Correspondence: Division of Unintentional Injury Prevention, National Center for Injury Prevention and Control, Centers for Disease Control and Prevention, 4770 Buford Hwy, N.E. Mailstop F-62, Atlanta, GA 30341, USA

10.1136/ip.2010.029215.116

Background Each year, more than a million people are killed in motor vehicle crashes worldwide. Crashes place a tremendous burden on societies not only in terms of lives lost but also in terms of cost. While there are many evidence-based road safety interventions that exist, many of these interventions are underutilised. Economic studies are a useful tool to illustrate the full range of consequences that crashes place on societies and can help prioritise injury prevention efforts.

Objectives To estimate the incidence and cost of motor vehicle-related fatal and non-fatal injuries in the United States in terms of medical care, treatment, rehabilitation services and productive life-years lost due to premature death or long-term disability.

Methods Incidence and cost data for 2005 were derived from several data sources. Unit costs were calculated for medical spending and productivity loss for fatal and non-fatal injuries, and unit costs were multiplied by incidence to yield total costs. Injury incidence and costs are presented by age, sex and road user type.

Results Motor vehicle-related fatal and non-fatal injury costs exceeded $\$ 99$ billion. Costs associated with motor vehicle occupant fatal and non-fatal injuries accounted for $71 \%$ ( $\$ 70$ billion) of all motor vehicle-related costs, followed by costs associated with motorcyclists ( $\$ 12$ billion), pedestrians ( $\$ 10$ billion) and pedalcyclists ( $\$ 5$ billion).

Discussion The substantial economic and societal costs associated with these injuries and deaths reinforce the need to implement evidence-based, cost-effective strategies. Evidencebased strategies that target increasing seat belt use, increasing child safety seat use, increasing motorcyclist and pedalcyclist helmet use and decreasing alcohol-impaired driving are available. 